\title{
\#MeToo in the Academic Library: A Quantitative Measurement of the Prevalence of Sexual Harassment in Academic Libraries
}

\section{Candice Benjes-Small, Jennifer E. Knievel, Jennifer Resor-Whicker, Allison Wisecup, and Joanna Hunter}

\begin{abstract}
The \#metoo movement has prompted national discussions about workplace sexual harassment. Social science research suggests that female-dominated professions experience a high degree of workplace sexual harassment from supervisors, coworkers, and clients. Anecdotal evidence suggests that librarians experience sexual harassment. The authors administered a vetted, widely used survey to quantitatively measure for the first time how widespread sexual harassment is within academic libraries.
\end{abstract}

\section{Introduction}

The \#metoo and \#timesup movements of 2017 led many librarians to openly discuss sexual harassment in the field. ${ }^{1}$ At ALA Annual in 2017, McLain and Civitello presented a session entitled "It's Not Just 'Part of the Job': Breaking the Silence on Sexual Harassment in the Library." 2 Informally, the authors of this study reported observing numerous conversations about sexual harassment at conferences and on social media throughout that summer and fall. By the end of 2017, articles on the topic were published in American Libraries and Book Riot. ${ }^{3}$

Social science research suggests that female-dominated professions experience a high degree of sexual harassment in the workplace. ${ }^{4}$ When the job includes working with clients or customers, the harassment can be intense. Anecdotal evidence suggests that people working in libraries experience similar types of harassment, but there has not been a large, quantitative study to date. To address this gap in the literature, a research team of librarians and sociologists administered the Sexual Experiences Questionnaire (SEQ) to measure the incidence and prevalence of sexual harassment in academic libraries. ${ }^{5}$

Sexual harassment can be difficult to define. While people generally agree that violent acts and quid pro quo cases deserve the label, they find it more problematic to characterize other,

Candice Benjes-Small is Head of Research in the William E Mary Libraries; email: CandiceBenjes-Small@wm.edu. Jennifer Knievel is Lead of Researcher $\mathcal{E}$ Collections Engagement and Professor in the University of Colorado Boulder Libraries; email: Jennifer.knievel@colorado.edu. Jennifer Resor-Whicker is Reference/Instruction Librarian at Radford University; email: jrwhicker@radford.edu. Allison Wisecup is Associate Professor of Sociology at Radford University; email: awisecup@radford.edu. Joanna Hunter is Assistant Professor of Sociology at Radford University; email:jhunter35@radford.edu. (02021 Candice Benjes-Small, Jennifer Knievel, Jennifer Resor-Whicker, Allison Wisecup, and Joanna Hunter, Attribution-NonCommercial (https://creativecommons.org/licenses/bync/4.0/) CC BY-NC. 
less clear-cut behaviors. ${ }^{6}$ One way to view sexual harassment is through a regulatory lens, drawn from the EEOC statement:

It is unlawful to harass a person (an applicant or employee) because of that person's sex. Harassment can include 'sexual harassment' or unwelcome sexual advances, requests for sexual favors, and other verbal or physical harassment of a sexual nature.

Harassment does not have to be of a sexual nature, however, and can include offensive remarks about a person's sex. For example, it is illegal to harass a woman by making offensive comments about women in general.

Both victim and the harasser can be either a woman or a man, and the victim and harasser can be the same sex.

Although the law doesn't prohibit simple teasing, offhand comments, or isolated incidents that are not very serious, harassment is illegal when it is so frequent or severe that it creates a hostile or offensive work environment or when it results in an adverse employment decision (such as the victim being fired or demoted). ${ }^{7}$

Sexual harassment can also be seen as a psychological construct. In this framework, unwanted, unwelcome sex-related behaviors at work do not have to reach the legalistic definition of frequency or severity; rather, it recognizes that workers who experience these behaviors at any rate or severity are negatively affected by them. ${ }^{8}$ As a result, the sexual harassment literature does not require victims to note a "pattern" of actions to qualify the behaviors as sexual harassment. Instead of looking at the behaviors as a binary "yes, it's sexual harassment" or "no, it's not," the research tends to look at sexual harassment in a more nuanced fashion.

\section{Literature Review}

Women in organizations that are tolerant of sexual harassment are significantly more likely to be harassed, even when analysis controls for the influence of the harassment victim herself. ${ }^{9}$ According to a meta-analysis conducted by Willness et al., harassment by colleagues is more likely to occur in masculine-associated fields with fewer women in the workplace, rather than feminine-associated fields that have a higher concentration of women in the workplace. ${ }^{10}$ Institutional context has been widely demonstrated to have a strong influence over whether harassment occurs. Institutions that are permissive of sexual harassment create an environment where victims are reluctant to report harassment, harassment claims are not believed, and harassers are rarely punished. ${ }^{11}$

A recent systematic review of research related to harassment among the staff in higher education found high rates of harassment of various kinds in institutions of higher education. ${ }^{12}$ In a 2017 study, Henning concluded that sexual harassment is the most common kind of harassment in academia and that it is accompanied by general workplace abuse. ${ }^{13}$ The researchers found that "workplace harassment is prevalent in higher education at all levels and among all disciplines" and that there is "compelling evidence of the continual problem 
associated with gender harassment" in academia. ${ }^{14}$ The same study found that more than 90 percent of the victims of workplace harassment were women, a finding that is consistently true across a wide variety of sexual harassment studies. ${ }^{15}$

\section{Harassment by Customers}

The vast majority of research related to sexual harassment in the workplace focuses, as is logical, on sexual harassment among coworkers. Fewer studies directly measure and assess sexual harassment by clients or customers, despite evidence that client sexual harassment is also widespread. ${ }^{16} \mathrm{~A}$ study by Gettman et al. explicitly measures the effects of harassment by clients/customers; they found that women who must spend time with customers to do their jobs suffer more severe sexual harassment when the clientele are men and when the power differential skews toward the client. ${ }^{17}$

Organizational context also has a strong influence. In a setting where customers have power to influence the work of the victims through punishment or reward, such as through sales or tipping, harassment is higher. Customers perceive themselves as powerful over the target and are more likely to behave inappropriately..$^{18}$ Such organizations often require or reward friendliness from employees, which can add to the problem. Men are more likely than women to interpret friendliness as flirting or an invitation to romantic engagement, which could lead to harassment. ${ }^{19}$

Client accountability is especially salient in the context of libraries. Perceived lack of accountability on the part of the customer, because they aren't being observed by others, they are alone with the target, or they believe institutional norms permit harassment, may lead them to be more likely to harass. ${ }^{20}$ Anyone who has worked a library public service desk or been in one-on-one meetings with patrons, or indeed with vendors or donors, can imagine how these settings could lead to more opportunities for harassment to occur.

In Gettman's study measuring sexual harassment by clients, 86 percent of women experienced some type of sexual harassment. That study concluded that "client sexual harassment is exacting both job-related and psychological costs" on employees and represents a "common and costly barrier to women's full participation in the workforce." ${ }^{21}$ Workplaces are responsible for protecting women from client sexual harassment but may not have in place procedures or policies for doing so, even if they have documented procedures for protecting women from sexual harassment by their coworkers. ${ }^{22}$

Research shows behaviors that constitute sexual harassment are frequently seen as an expected "part of the job." Such thinking seems to be common in female-dominated professions. In a recent article in the American Journal of Nursing, Nelson reports that sexual harassment is underreported among nurses, despite many medical facilities having zero tolerance policies in place. ${ }^{23}$ In a study of social work students, Moylan and Wood found that many were labeling sexual harassment behaviors as "typical" for clients, worrying the researchers that the students were learning to tolerate being harassed..$^{24}$ Drawing from our own library experiences again, we found commonality in being told by coworkers after an uncomfortable interaction with a patron that "Oh, so-and-so is harmless" and were advised just to let it go.

Numerous studies have found that gender context influences the amount of harassment one experiences, generally finding that harassment is worse for women in traditionally male occupations such as the military. ${ }^{25}$ However, the important factor of gender context with client harassment is less well-studied. In the case of client sexual harassment, even women 
in traditionally female professions seem to be at high risk for harassment by clients. ${ }^{26} \mathrm{~A}$ low level of perceived risk by customers leads to increased instances of sexual harassment and other aggressive behaviors. ${ }^{27}$ Absence of policies for what to do about client sexual harassment may make the likelihood of it happening worse or suppress reporting. Anonymity of customers also exacerbates a culture of sexual harassment because of the low perceived risk by the anonymous customers.

\section{Harassment in Libraries}

Surprisingly little evaluation of sexual harassment in libraries exists, given that what little research is available suggests that sexual harassment of librarians is pervasive. Vaughn's study particularly calls out librarianship as a field that experiences widespread harassment by customers. ${ }^{28}$ Given how many risk factors for sexual harassment are prominent in academic libraries, the research team posited that the likelihood of harassment would be high in academic libraries, where many librarians are female and customers are frequently anonymous and likely to perceive themselves to be at low risk for consequences if they harass. Vaughn et al. find that "sexual harassment is not just a phenomenon that occurs among co-workers; customers and clients harass employees across a wide spectrum of businesses and occupations." ${ }^{29}$ Manley's informal survey of librarians conducted in the early 1990s found that 78 percent of survey respondents reported experiencing frequent sexual harassment at work, mostly by customers, who are also frequently called "patrons" in libraries. ${ }^{30}$ Manley reported that, when he shared the results of his survey at professional gatherings, most librarians expressed genuine surprise that the number wasn't higher. Another, much more recent but still informal, survey in 2017 was distributed on social media in response to a firestorm resulting from women librarians publicly naming a male librarian they considered a serial sexual harasser. ${ }^{31}$ That survey received 250 responses detailing stories of harassment, many of them in public libraries, and many of them by patrons, though harassment by colleagues also was represented in those survey results. This anecdotal evidence, along with other articles describing widespread sexism in the field, suggests widespread harassment in the industry of libraries. ${ }^{32}$

Libraries as a profession have a very strong focus on the service element of their work. Librarians are generally expected to be friendly and professional no matter how patrons behave, which may partially explain the reason these informal surveys also persistently highlight a lack of action in leadership. ${ }^{33}$ Friendliness is a key characteristic of approachability for librarians, and librarians are trained to exhibit friendliness to overcome patrons' potential reluctance to demonstrate their own ignorance by asking for help with research. ${ }^{34}$ Service pressure is not the same as customer service, and the extent to which librarians might be considered to be in a service pressure environment might vary by institution. "One of the highest professional values of librarians is a service orientation.... Librarians are trained to uphold this ideal [of public service] by treating library users with respect regardless of their appearance, dress, economic, ethnic, or educational background, ideas, or beliefs." However, recognition and prohibition of harassment of staff by library patrons, either by policy or procedure, is rare. ${ }^{36} \mathrm{~A}$ mid-1990s article points out that the public nature of library facilities is a contributing factor to problematic patron behavior:

Public facilities which encourage public access have the highest risk of criminal activity.... many people who cannot, or do not want to, conform to societal norms feel safe in libraries. ${ }^{37}$ 
Despite the evidence that harassment in libraries is widespread, to the knowledge of the authors, no formal widespread survey using established tools to measure sexual harassment, such as the SEQ, the most common method for measuring incidence of sexual harassment, has yet been conducted in the industry before now. ${ }^{38}$

\section{Harm of Harassment}

The harm done by sexual harassment to victims, as well as to their workplaces, is extremely well documented in nearly every published article on the subject. This harm to career success and satisfaction for women comes in the form of "decreased job satisfaction, lower organizational commitment, withdrawing from work, physical and mental ill health, and symptoms of PTSD." ${ }^{39}$ Additionally, organizational climate "figures prominently in facilitating these occurrences" by influencing the likelihood of reporting, perceptions of whether or not reporting would be taken seriously, and likelihood of sanctions..$^{40}$ These harms are costly to the workplace as well as to the targets of harassing behaviors, and additionally they are harmful to other members of the organization who are not the targets. ${ }^{41}$ As Willness explained, "we know that organizational factors are fundamental, and therefore, we should move toward identifying the organizational policies and procedures that are most critical for preventing the conditions that create a favorable organizational climate for sexual harassment. This in turn should lead to decreased occurrences of sexual harassment." 42 Working to reduce sexual harassment is not only a legal obligation in many jurisdictions because it constitutes a form of gender-based discrimination, but it is also a good business decision, since sexual harassment has so many negative repercussions for group productivity, morale, turnover, absenteeism, and healthcare costs. ${ }^{43}$

Existing research demonstrates clearly that harassment in the workplace is a large-scale problem. ${ }^{44}$ Informal evidence strongly suggests that harassment in libraries is both pervasive and common. Beginning with the clear understanding that workplace sexual harassment has gradations in both nature and severity, and that those gradations matter in how both the victim and the institution can and should respond, the authors wished to measure the prevalence of such behaviors in academic libraries, from coworkers as well as patrons.

\section{Method}

While the existing literature talks about sexual harassment in libraries generally, the authors chose to split our research between academic libraries and public libraries. We decided to focus on academic libraries for this first survey, with plans for a follow-up survey targeting public libraries.

Our survey explored two research questions:

- Research Question 1: What is the prevalence of sexual harassment by coworkers among library workers in academic libraries?

- Research Question 2: What is the prevalence of sexual harassment by patrons among library workers in academic libraries?

We received Institutional Review Board (IRB) approval from all three schools. The IRBs were very proactive in the process, suggesting ways to strengthen the confidentiality and ensuring risk to participants was minimized. As a result, the researchers did not capture identifying features, such as the names of institutions, and provided links to resources such as RAINN for anyone who might have been affected by the discussion of sexual harassment. 
We sent out the survey over numerous academic library email listservs operated by ALA to target academic library workers specifically, including ILI-L, INFOLIT, STS, LITA, LLAMA, RUSA, COLLIB-L and SRRT.

The invitations clearly stated that academic library employees were the intended audience and should complete the survey regardless of whether they had experienced sexual harassment or not. This survey was meant for all genders and positions in academic libraries. There is no way to identify a specific sample due to the fact that it is impossible to reach all academic library workers. The authors felt that distributing the survey to various email listservs would cast the largest net, allowing it to reach a representative population of academic library workers.

The survey ran for 24 days, opening on April 2, 2018, and closing on April 27, 2018. ${ }^{45}$ It received 690 responses. Of those responses, 15 respondents began the survey and then declined to participate after the first screening question. That first question was designed to allow prospective participants to opt out of the survey after reading a description of what the survey would cover. Sixty-two respondents proceeded from the first screening question but then did not answer any of the remaining questions. A total of 613 respondents completed the survey, bringing the completion rate for those who began the survey to 88.8 percent.

Our research team decided to use the Sexual Experiences Questionnaire (SEQ) for our study, as it is the most widely used and vetted tool for studying sexual harassment. Developed first in 1988 by Fitzgerald and Geltman and revised multiple times during the 1990s and 2000s, the SEQ was created as a self-reported inventory to capture the prevalence of sexual harassment. Sexual harassment in this tool is defined as "unwanted sex-related behavior at work that is appraised by the recipient as offensive, exceeding her resources, or threatening her well-being." 46 The questionnaire asks participants to indicate whether they have experienced particular behaviors that fit the definition.

The SEQ has its critics. Its foundational definition of sexual harassment is cis-gendered, situates cis-women as the victims, and goes beyond the EEOC definition. Consequently, it has been revised and modified multiple times to better reflect the populations being studied. These changes in turn have made some question its validity; how much can it be edited before testing it again $?^{47}$ Despite these concerns, the majority of studies about sexual harassment have used it. ${ }^{48}$ The SEQ was especially fitting for this study, as it has been used for numerous studies that examine sexual harassment by clients or customers. ${ }^{49}$

The SEQ is a 30-item tool that assesses individuals' experiences with five dimensions of sexual harassment: Gender Harassment, Seductive Behavior, Sexual Bribery, Sexual Coercion, and Sexual Assault. ${ }^{50}$ The dimensions of sexual harassment measured by the SEQ increase in degree or level of intensity from general sexist remarks to gross sexual assault. Each dimension is measured using several items that indicate whether the respondent has had the experience described (1) or not had the experience described (0). It defines the dimensions by way of these concepts:

- Gender harassment is conceptualized as generalized sexist remarks and behavior and operationalized with seven items.

- Seductive behavior is operationalized as experiencing inappropriate and offensive, but essentially sanction-free sexual advances and is measured with nine dichotomously measured items.

- Sexual bribery is conceptualized as solicitation of sexual activity or other sex-linked behavior by the promise of rewards and is operationalized with four items. 
- Sexual coercion is conceptualized as coercion of sexual behavior by threat of punishment and is measured with four items.

- Sexual assault is conceptualized as gross sexual imposition or assault and is measured with five items.

Finally, the SEQ contains a single item that serves as a global indicator of Sexual Harassment. The global sexual harassment item asks whether the respondent was sexually harassed. Until that last question, the phrase "sexual harassment" is not used, as the intent is to prompt respondents to think strictly about actual experiences. The final question is then used to see whether participants consider the behaviors experienced to be, in fact, "sexual harassment."

Following the lead of other studies that have used the SEQ, we asked participants to report on the past five years. Because of recall issues, lifetime rates are generally less reliable than shorter time frames. Respondents tend to remember more when asked about recent events and are especially helped when asked to relate experiences to specific settings and timeframes. ${ }^{51}$

\section{Survey Participant Demographics}

The survey collected data about respondents' gender, race, and age. Gender was measured with two questions consistent with the guidelines suggested by The Williams Institute to identify transgender individuals. ${ }^{52}$ The first question asked respondents to indicate the sex they were assigned at birth (male or female), and the second question asks about respondents' current gender identity (male, female, transgender, or do not identify as female, male, or transgender). Cross tabulation of these variables permits identifying cisfemales, cismales, transgender men and women, and other gender minorities. Nearly 98 percent of respondents identified as cisgender ( $85 \%$ cisfemale and $13 \%$ as cismale). Respondents who identified as transgender men, transgender women, or some other gender minority were excluded from analyses due to insufficient numbers of observations. Race was measured using a single question asking respondents to self-identify their race as: white, Black/African-American, American Indian or Alaskan Native, Asian, Native Hawaiian or Pacific Islander, or Other. Individuals could select any combination of these responses to indicate a multiracial identity. Most respondents in the sample $(89 \%)$ indicated they were white, and the remaining 11 percent indicated they were either a racial minority, biracial, or multiracial. These numbers align with academic librarian demographics, which report 86 percent of librarians are white, and 82.2 percent are female, indicating our sample reflects the profession. ${ }^{53}$

Age was self-reported in years. The average age of respondents was 41.54 years with a range of 22 to 75 years old. Nearly three-quarters of the sample (74.6\%) was younger than 50 years old and more than half of the sample (49.8\%) was younger than 40 years old, suggesting that the sample is disproportionately young.

Respondents provided information about specific characteristics of their current position and institution and had the opportunity to report these characteristics for up to five previous positions. Respondents indicated the percent of their time spent interacting with library patrons using a sliding scale that ranged from none to 100 percent. The average amount of time spent interacting with patrons in all positions was approximately 49 percent with approximately 60 percent of the sample reporting they spend 50 percent or less of their time interacting with patrons. Respondents also reported about three characteristics of institutions at which they were currently or had been employed: 1) academic nature of the institution (in other words, doctoral, master's, and so on), geographical setting (in other words, rural, suburban, urban), and type of institution (public or private). To maintain the highest degree of anonymity pos- 
sible, the survey did not ask for the names of institutions. Nearly half of respondents indicated they were either currently employed or had been employed at a doctorate-granting institution. The majority of respondents indicated that their current or previous appointments were in institutions in a city context. Finally, nearly two-thirds (63.7\%) of respondents indicate current or previous employment in public institutions.

\section{Analysis}

Respondents' answers for each dimension were summed. If the resulting value was greater than zero, they were coded as having the experience measured by the dimension; if the value was zero, they were coded as not having the experience measured by the dimension. Table 1 contains the overall prevalence of each dimension of sexual harassment regardless of actor (patron vs coworker) in the sample.

\begin{tabular}{|l|c|}
\hline \multicolumn{2}{|c|}{$\begin{array}{c}\text { TABLE } 1 \\
\text { Prevalence of Sexual Harassment } \\
\text { by Dimension }\end{array}$} \\
\hline & $\begin{array}{c}\text { \% Reporting Any } \\
\text { Experience (n) }\end{array}$ \\
\hline Gender Harassment & $78.1(746)$ \\
\hline Seductive Behavior & $64.4(549)$ \\
\hline Sexual Bribery & $2.4(20)$ \\
\hline Sexual Coercion & $1.5(12)$ \\
\hline Sexual Assault & $35.2(298)$ \\
\hline Sexual Harassment & $21.2(178)$ \\
\hline
\end{tabular}

As table 1 indicates, gender harassment is the most frequently reported experience with sexual harassment in the sample. Further, the prevalence of specific dimensions of sexual harassment declines as the severity or intensity of the behaviors experienced increases, with the exception of sexual assault. Whereas a very small proportion of the sample reports experience with sexual coercion or sexual bribery, a sizable proportion (35\%) indicate experience with sexual assault at the hands of either a patron, coworker, or both. A more detailed analysis of this dimension of sexual harassment suggests the nearly all (99\%) experiences in the sexual assault dimension are characterized by "deliberate touching that made the respondent uncomfortable" rather than "fondling, or attempted or forced sexual intercourse." One striking feature of table 1 is the obvious discrepancy between some dimensions of sexual harassment and the global measure of sexual harassment. Specifically, 78 percent of the sample indicates experience with behaviors that qualify as gender harassment and 64 percent indicate an experience with seductive behavior, but only 21 percent of the sample marked "yes" to the final question asking if they had experienced "sexual harassment," using that specific phrase. The discrepancy between the specific dimensions of sexual harassment

\begin{tabular}{|l|c|c|c|c|c|}
\hline \multicolumn{7}{|c|}{ TABLE 2} \\
& \multicolumn{7}{|c|}{$\begin{array}{c}\text { Gender } \\
\text { Harassment }\end{array}$} & $\begin{array}{c}\text { Seductive } \\
\text { Behavior }\end{array}$ & $\begin{array}{c}\text { Sexual } \\
\text { Bribery }\end{array}$ & $\begin{array}{c}\text { Sexual } \\
\text { Coercion }\end{array}$ & $\begin{array}{c}\text { Sexual } \\
\text { Assault }\end{array}$ \\
\hline Gender Harassment & & & & & \\
\hline Seductive Behavior & $93.2^{* *}$ & & & & \\
\hline Sexual Bribery & $100^{* *}$ & $100^{* *}$ & & & \\
\hline Sexual Coercion & 100 & $100^{*}$ & 0 & & \\
\hline Sexual Assault & $93.2^{* *}$ & $86.6^{* *}$ & $6^{* *}$ & $3.2^{*}$ & \\
\hline Sexual Harassment & $100^{* *}$ & $97.2^{* *}$ & $6.2^{* *}$ & $4.2^{* *}$ & $71.9^{* *}$ \\
\hline${ }^{*} p<.01,{ }^{* *} p<.001$ & & & & \\
\hline
\end{tabular}


and the global measure may suggest that individuals who experience gender harassment or seductive behavior do not necessarily characterize these experiences as sexual harassment.

Table 2 illustrates the relationship among the five dimensions of sexual harassment. Each column tells us what percentage of individuals who had experienced a behavior from this dimension also experienced a behavior in one of the other dimensions. For example, 93.2 percent of individuals who report experiencing gender harassment also experienced seductive behavior and sexual assault, and all marked "yes" to the final question asking if they had experienced "sexual harassment." Similar strongly positive relationships are evident for seductive behavior and sexual harassment. (Caution should be used when interpreting the relationship between any specific dimension of sexual harassment and the sexual bribery and sexual coercion dimensions due to the extremely low level of reporting for these specific dimensions).

Interestingly, the relationships in table 2 indicate that all individuals who experience gender harassment also report experiencing sexual harassment, suggesting that gender harassment is implicitly viewed as sexual harassment by respondents. The same, however, cannot be said for the other dimensions of sexual harassment. Specifically, the experience of seductive behavior and sexual assault are not implicitly viewed as a form of sexual harassment.

\section{Results and Discussion}

\section{Gender Harassment, Seductive Behavior, and Sexual Assault}

Respondents who experienced gender harassment, seductive behavior, and sexual assault displayed similar characteristics. Statistically significant relationships were seen in gender, age, and time spent with patrons. Women were more likely to experience gender harassment, seductive behavior, and sexual assault. Individuals who experience these types of sexual harassment are significantly younger than those who do not. Individuals who spend more time with patrons are also more likely to experience these types of sexual harassment. There were no statistically significant differences in the experiences of these types of sexual

\section{FIGURE 1}

Prevalence of Sexual Harassment by Dimension

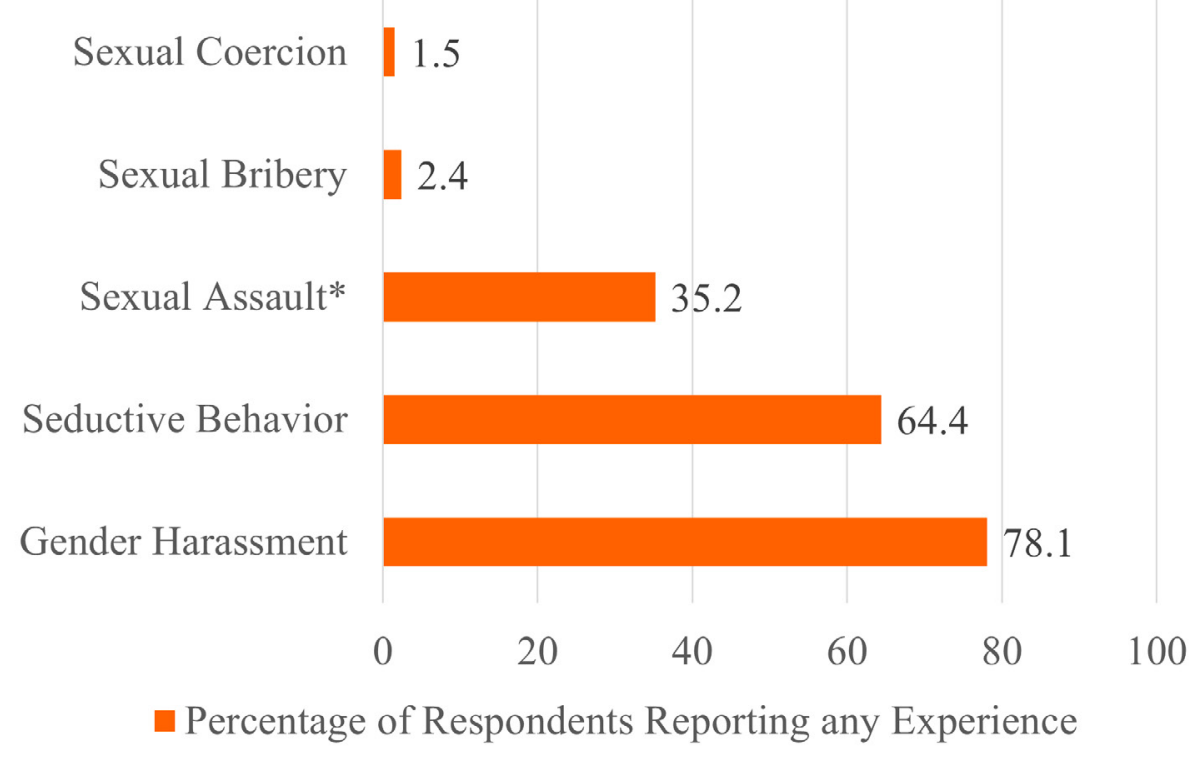


harassment and race. Only one of the institutional variables was significantly associated with gender harassment and seductive behavior: individuals with positions at public institutions are more likely to experience these two types of sexual harassment. None of the institutional characteristics were significantly associated with the sexual assault dimension of sexual harassment. Tables displaying the relationships between these experiences and individual and institution characteristics can be found in the appendices.

A more detailed analysis of this dimension of sexual harassment suggests the nearly all (99\%) experiences in the sexual assault dimension are characterized by "deliberate touching that made the respondent uncomfortable" rather than "fondling, or attempted or forced sexual intercourse."

Trends with gender, age, type of institution, and time spent with the public became evident throughout the various dimensions of sexual harassment that the survey measured. As has been found in most similar analyses, women were more likely than men to experience sexual harassment. Respondents who spent a significant amount of time with patrons were also more likely to experience sexual harassment. The data also indicated that age is a factor. Respondents who reported experiencing sexual harassment had a median age of approximately 37. It was also found that respondents who work at public universities are more likely to experience sexual harassment than those who work at private institutions. Logic would suggest that the reason sexual harassment is more common at public institutions is due to the fact that academic libraries at public colleges and universities see more public patrons, and are seen as more public buildings, than their private counterparts. When the data is broken down by the type of perpetrator of the behavior, it reveals that the perpetrators of harassment depend on the type of harassment and the opportunity to commit harassment. It was reported that explicit remarks were more likely to come from coworkers, while leering and ogling at librarians is more likely to come from patrons. Both of these examples could be due to an opportunity effect, wherein coworkers have more opportunities to interact and thus engage in conversations with an individual, while patrons might not have as many opportunities to speak with an individual but have more opportunities to stare and engage in brief interactions

\section{FIGURE 2}

Gender Harassment and Seductive Behavior by Perpetrator

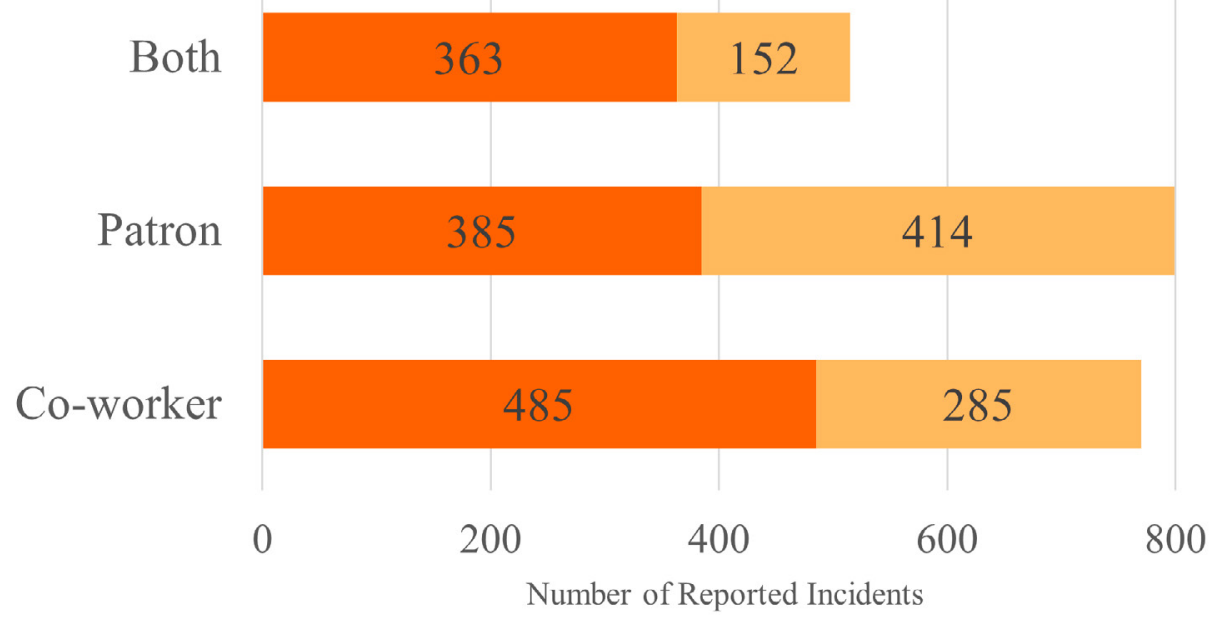

Gender Harassment $\square$ Seductive Behavior 
that make their targets uncomfortable. Gender harassment and seductive behaviors were the most commonly experienced types of sexual harassment among survey respondents.

The data collected from one question in particular drove home why a survey like this is needed in academic libraries. In the global measure question, respondents were asked, "Have you ever been in a situation where a coworker or library patron sexually harassed you?" More than three-fourths (83.1\%) of participants responded "no." However, 77.4 percent responded yes to at least one survey item, indicating that more than three-fourths of the survey respondents did, in fact, experience some form of sexual harassment. The data demonstrate that respondents consistently interpret gender harassment as sexual harassment, but not seductive behaviors or unwelcome touching.

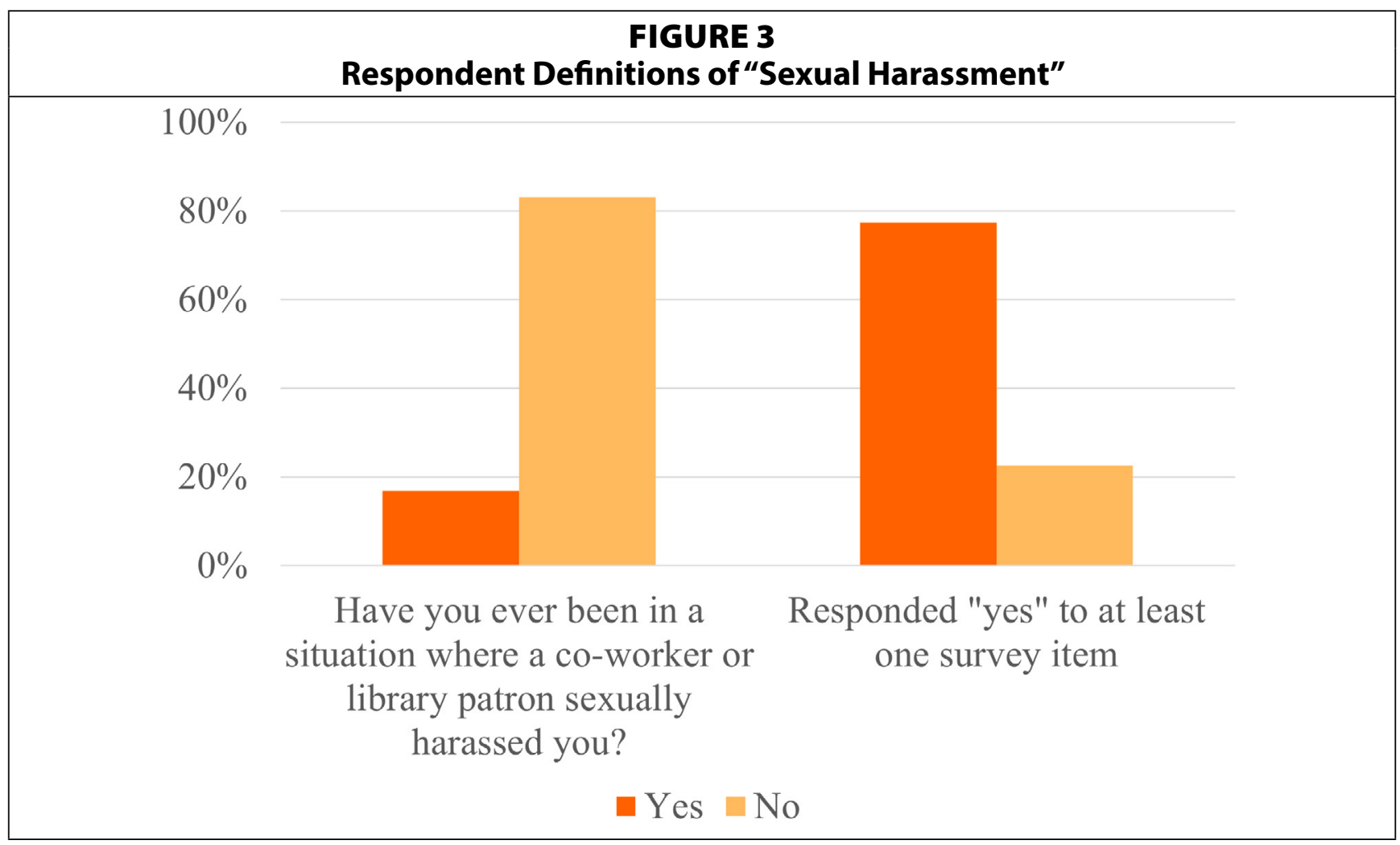

The SEQ has a question that is designed to be the global indicator for sexual harassment. In that question, respondents were asked, "Have you ever been in a situation where a coworker or library patron sexually harassed you?" More than four out of five (83\%) participants responded "no" that they had not been sexually harassed by a coworker or library patron. However, 77.4 percent responded "yes" to at least one survey item indicating that they had been sexually harassed in some form.

We believe this disconnection has a few causes. First, the definition of sexual harassment is an ongoing conversation in our society. The legal definition as laid out by the EEOC is the most commonly discussed one, and it's quite possible that the participants have absorbed it as the only definition. We have talked about harassment training on our three campuses and have found that the behaviors in such trainings are often drawn from the EEOC. If there are no concrete repercussions or no easily identifiable pattern, then "sexual harassment" may not be seen as such by employees. 
One should not assume that the respondents saw the behaviors as acceptable, though. It is possible that respondents saw the behaviors as misconduct related to but not strictly defined as sexual harassment. As in the studies from the literature review, we believe it is plausible that some might also consider the behaviors as inappropriate but not rising to the level of reporting. Labeling an action as sexual harassment may indicate the library worker must report it.

\section{Limitations}

While the sample of this study is similar to the profession's national demographics, we need to be cautious about generalizing the results to academic librarianship as a whole. Due to the priority of keeping data anonymous, we cannot conclude we have a representative sample. As with any publicly circulated survey, participants self-select, resulting in a sample of people who may have a higher-than-average interest in sexual harassment issues. It is feasible that our survey drew a disproportionate number of library workers who had experienced sexual harassment themselves.

While our survey was intended to measure prevalence among all library workers, we suspect our pool is heavy on librarians. We primarily distributed the survey through ALA listservs; and, while we did not limit it to professional librarians, the audience of listservs tends to be librarians. We do not know how many paraprofessionals and student workers took the survey.

\section{Implications and Recommendations}

The implications of the severity and prevalence of sexual harassment in libraries are enormous. A wide body of existing research demonstrates the high costs of harassment to both individuals and to organizations, in the form of personal harm to the targets, as well as fiscal harm to the employer in the form of absenteeism, healthcare costs, engagement, and turnover. Given the high incidence of harassment, it follows that our field is routinely paying these costs both as individuals and as an industry.

Institutions are legally required to protect library workers from sexual harassment from both colleagues and patrons. While it is likely that many libraries can follow or adopt institutional harassment policies related to colleagues, we are not aware of model policies for reporting, responding to, or preventing harassment from academic library patrons. The absence of a policy adds yet another deterrent to the already high barriers to reporting or preventing harassment.

There are actions that individuals and workplaces can take to respond to the harassment that is happening in libraries and begin to move toward an environment that is less tolerant of sexual harassment:

- Develop policies that address harassment from all perpetrators. While our study looked at behaviors from colleagues and patrons, subsequent conversations with librarians have identified many other problematic interactions. What should a library employee do in a situation with a professor, a vendor, a donor, a student, or other possible harasser?

- Implement awareness initiatives. Policies accomplish little without attendant action, and it is essential that all employees understand what constitutes sexual harassment, how to report it, and what the consequences can be.

- Build a culture that is anti-harassment. Ongoing training, not just at the time of hire, will 
keep employees' awareness fresh and show a commitment to protecting employees. Bystander training, in which people are taught how to intervene when they witness negative behaviors, can be effective. ${ }^{54}$ In all cases, developing and sharing scripts for employees so that they are not faced with needing to instantly summon effective language can be a helpful tool to empower targets and remind them of reporting procedures.

- Commit to response procedures. An essential component to any prevention and reporting is the response when harassment is reported. EEOC estimates that 75 percent of harassment is unreported because of concern that managers will not respond or will not believe them or fear retribution..$^{55}$ Managers must hold harassers responsible to create a culture where harassment is reduced.

Our workplaces shouldn't have to be this way. It is essential that all library workers, including library leaders, stop treating harassment as an inevitable condition of the workplace and that leaders respond to harassment with legal, professional, and personal support for targets as the situation indicates. We hope this study inspires library professionals in all kinds of libraries to see harassment for what it is and to stop accepting it as a necessary evil in their professional lives. The authors further hope that this evidence of the prevalence and incidence of harassment in libraries galvanizes academic library administrators and managers to seek ways to address the prevalence within their own institutions, and our field. 


\section{Appendix: Data Analysis Tables}

\begin{tabular}{|c|c|c|}
\hline \multicolumn{3}{|c|}{$\begin{array}{c}\text { APPENDIX TABLE } 1 \\
\text { Characteristics of Respondents' Positions and Institutions }\end{array}$} \\
\hline & Mean (SD) & $\%(N)$ \\
\hline Time Spent with Patrons & \multicolumn{2}{|l|}{$48.55(26.31)$} \\
\hline \multicolumn{3}{|l|}{ Academic Nature } \\
\hline Doctoral & & $48.5(481)$ \\
\hline Masters & & $23.6(234)$ \\
\hline Baccalaureate & & $19.4(192)$ \\
\hline Associate & & $7.8(84)$ \\
\hline \multicolumn{3}{|l|}{ Institutional Setting } \\
\hline Rural & & $6.8(66)$ \\
\hline Town & & $22.7(221)$ \\
\hline Suburban & & $18.9(184)$ \\
\hline City & & $51.7(504)$ \\
\hline \multicolumn{3}{|l|}{ Type of Institution } \\
\hline Public & & $63.7(618)$ \\
\hline Private & & $36.3(352)$ \\
\hline
\end{tabular}

\begin{tabular}{|l|l|l|}
\hline \multicolumn{3}{|c|}{$\begin{array}{c}\text { APPENDIX TABLE 2 } \\
\text { Relationship between the Experience of Gender Harassment and Individual and } \\
\text { Institutional Characteristics }\end{array}$} \\
\hline \multicolumn{1}{|c|}{ Percent (N) } & \multicolumn{1}{|c|}{ p $_{\text {pb }}$} \\
\hline Individual Characteristics & \multicolumn{1}{|c|}{} \\
\hline White & $78.1(667)$ & \\
\hline Minority/Multiracial & $76.3(71)$ & \\
\hline Women & $79.1(647)^{* *}$ & \\
\hline Men & $67.3(74)$ & $-0.309^{* *}$ \\
\hline Age & & $.104^{* *}$ \\
\hline Time Spent with Patrons & & \\
\hline Academic Nature & & \\
\hline Doctoral & $79.6(359)$ & \\
\hline Masters & $80(180)$ & \\
\hline Baccalaureate & $70.9(129)$ & \\
\hline Associate & $77.2(61)$ & \\
\hline Institutional Setting & & \\
\hline Rural & $76.9(50)$ & \\
\hline Town & $75.8(163)$ & \\
\hline Suburban & $78.4(131)$ & \\
\hline City & $78.8(376)$ & \\
\hline Type of Institution & & \\
\hline Public & $80(475)^{*}$ & \\
\hline Private & $74.2(241)$ & \\
\hline$*$ p $<.05, * * p<.01, * * * 0.001$ & & \\
\hline & & \\
\hline
\end{tabular}




\begin{tabular}{|l|l|l|}
\hline \multicolumn{3}{|l|}{$\begin{array}{l}\text { APPENDIX TABLE 3 } \\
\text { Relationship between the Experience of Seductive Behavior and Individual and } \\
\text { Institutional Characteristics }\end{array}$} \\
\hline \multicolumn{2}{|l|}{ Percent (N) } & r $_{\text {pb }}$ \\
\hline Individual Characteristics & $65.4(495)$ & \\
\hline White & $55.6(50)$ & \\
\hline Minority/Multiracial & $67(489)^{* * *}$ & \\
\hline Women & $44(44)$ & \\
\hline Men & & $-.241^{* *}$ \\
\hline Age & & $.140^{* *}$ \\
\hline Time Spent with Patrons & & \\
\hline Academic Nature & $65.2(260)$ & \\
\hline Doctoral & $64.3(133)$ & \\
\hline Masters & $64.9(109)$ & \\
\hline Baccalaureate & $58.7(37)$ & \\
\hline Associate & & \\
\hline Institutional Setting & $60.3(38)$ & \\
\hline Rural & $61.5(118)$ & \\
\hline Town & $64.1(98)$ & \\
\hline Suburban & $65.1271)$ & \\
\hline City & $66.7(350)^{*}$ & \\
\hline Type of Institution & $58.3(172)$ & \\
\hline Public & & \\
\hline Private & & \\
\hline$* p<.05, * * p<.01, * * * p<.001$ & & \\
\hline & & \\
\hline
\end{tabular}

\begin{tabular}{|c|c|c|}
\hline \multicolumn{3}{|c|}{$\begin{array}{c}\text { APPENDIX TABLE } 4 \\
\text { Relationship between the Experience of Sexual Assault and Individual and Institutional } \\
\text { Characteristics }\end{array}$} \\
\hline & Percent (N) & $\mathbf{r}_{\mathrm{pb}}$ \\
\hline \multicolumn{3}{|l|}{ Individual Characteristics } \\
\hline White & $35.9(270)$ & \\
\hline Minority/Multiracial & $28.1(25)$ & \\
\hline Women & $36.7(266)^{* * *}$ & \\
\hline Men & $22(22)$ & \\
\hline Age & & $-.158^{* *}$ \\
\hline \multicolumn{2}{|l|}{ Time Spent with Patrons } & $.107^{*}$ \\
\hline \multicolumn{2}{|l|}{ Academic Nature } & \\
\hline Doctoral & $33.9(134)$ & \\
\hline Masters & $38.6(78)$ & \\
\hline Baccalaureate & $34.5(59)$ & \\
\hline Associate & $34.9(22)$ & \\
\hline
\end{tabular}




\begin{tabular}{|l|l|l|}
\hline \multicolumn{3}{|c|}{$\begin{array}{c}\text { APPENDIX TABLE 4 } \\
\text { Characteristics } \\
\text { Relationship between the Experience of Sexual Assault and Individual and Institutional }\end{array}$} \\
\hline \multicolumn{2}{|c|}{ Percent (N) } & r $_{\mathrm{pb}}$ \\
\hline Institutional Setting & $31.1(19)$ & \\
\hline Rural & $34.7(66)$ & \\
\hline Town & $30.5(46)$ & \\
\hline Suburban & $38.1(160)$ & \\
\hline City & & \\
\hline Type of Institution & $35.1(184)$ & \\
\hline Public & $35(103)$ & \\
\hline Private & & \\
\hline${ }^{*} \mathrm{p}<.05,{ }^{* *} \mathrm{p}<.01,{ }^{* * *} \mathrm{p}<.001$ & \\
\hline
\end{tabular}

\begin{tabular}{|c|c|c|}
\hline \multicolumn{3}{|c|}{$\begin{array}{c}\text { APPENDIX TABLE } 5 \\
\text { Relationship between the Experience of Global Sexual Harassment and Individual and } \\
\text { Institutional Characteristics }\end{array}$} \\
\hline & Percent (N) & $\mathbf{r}_{\mathrm{pb}}$ \\
\hline \multicolumn{2}{|l|}{ Individual Characteristics } & \\
\hline White & $21.5(160)$ & \\
\hline Minority/Multiracial & $20.5(18)$ & \\
\hline Women & $22.5(161)^{* * *}$ & \\
\hline Men & $8(8)$ & \\
\hline Age & & $-.158^{* *}$ \\
\hline \multicolumn{2}{|l|}{ Time Spent with Patrons } & $.107^{*}$ \\
\hline \multicolumn{2}{|l|}{ Academic Nature } & \\
\hline Doctoral & $18.4(72)$ & \\
\hline Masters & $26.5(53)$ & \\
\hline Baccalaureate & $21.2(36)$ & \\
\hline Associate & $19.4(12)$ & \\
\hline \multicolumn{2}{|l|}{ Institutional Setting* } & \\
\hline Rural & $13.3(8)$ & \\
\hline Town & $16.4(31)$ & \\
\hline Suburban & $17.4(26)$ & \\
\hline City & $25(104)$ & \\
\hline \multicolumn{2}{|l|}{ Type of Institution } & \\
\hline Public & $22.4(116)$ & \\
\hline Private & $17.1(50)$ & \\
\hline${ }^{*} p<.05,{ }^{* *} p<.01,{ }^{* * *} p<.001$ & & \\
\hline
\end{tabular}




\section{Notes}

1. Alex Langone, “\#MeToo and Time's Up Founders Explain the Difference Between the 2 Movements," Time, accessed June 15, 2020, https://time.com/5189945/whats-the-difference-between-the-metoo-and-times-upmovements/.

2. Amanda Civitello and Katie McLain, "It's Not Just Part of the Job: Speaking Out About Sexual Harassment-Illinois Library Association," Illinois Library Association Reporter (December 2017).

3. Anne Ford, "Stop Sexual Harassment in Your Library," American Libraries Magazine (November 1, 2017), https://americanlibrariesmagazine.org/2017/11/01/stop-sexual-harassment-your-library/; Kelly Jensen, "The State of Sexual Harassment in the Library," Book Riot (October 24, 2017), https://bookriot.com/2017/10/24/sexualharassment-library/.

4. Dana Yagil, "When the Customer Is Wrong: A Review of Research on Aggression and Sexual Harassment in Service Encounters," Aggression and Violent Behavior 13, no. 2 (March 2008): 141-52, https://doi.org/10.1016/j. avb.2008.03.002.

5. Louise F. Fitzgerald, Michele J. Gelfand, and Fritz Drasgow, "Measuring Sexual Harassment: Theoretical and Psychometric Advances," Basic and Applied Social Psychology 17, no. 4 (1995): 425-45.

6. Kathryn Casteel, “We Need a Better Way to Talk about 'Sexual Misconduct,"' FiveThirtyEight (April 17, 2018), https://fivethirtyeight.com/features/we-need-a-better-way-to-talk-about-sexual-misconduct/.

7. Chai Feldblum and Victoria Lipnic, "Select Task Force on the Study of Harassment in the Workplace: Executive Summary \& Recommendations" (U.S. Equal Employment Opportunity Commission, June 2016), https:// www.eeoc.gov/eeoc/task_force/harassment/.

8. Chelsea R. Willness, Piers Steel, and Kibeom Lee, "A Meta-Analysis of the Antecedents and Consequences of Workplace Sexual Harassment," Personnel Psychology 60, no. 1 (2007): 127-62.

9. Nancy Chi Cantalupo and William C. Kidder, "A Systematic Look at a Serial Problem: Sexual Harassment of Students by University Faculty," Utah Law Review (Spring 2018): 96.

10. Willness, Steel, and Lee, "A Meta-Analysis of the Antecedents and Consequences of Workplace Sexual Harassment."

11. Willness, Steel, and Lee, "A Meta-Analysis of the Antecedents and Consequences of Workplace Sexual Harassment."

12. Marcus A. Henning et al., "Workplace Harassment among Staff in Higher Education: A Systematic Review," Asia Pacific Education Review 18, no. 4 (December 2017): 521-39, https://doi.org/10.1007/s12564-017-9499-0.

13. Henning et al., "Workplace Harassment among Staff in Higher Education."

14. Henning et al., "Workplace Harassment among Staff in Higher Education."

15. See, for example, Willness, Steel, and Lee, "A Meta-Analysis of the Antecedents and Consequences of Workplace Sexual Harassment"; Louise F. Fitzgerald et al., "The Incidence and Dimensions of Sexual Harassment in Academia and the Workplace," Journal of Vocational Behavior 32, no. 2 (April 1988): 152-75, https://doi. org/10.1016/0001-8791(88)90012-7; Louise F. Fitzgerald, Suzanne Swan, and Vicki J. Magley, "But Was It Really Sexual Harassment? Legal, Behavioral, and Psychological Definitions of the Workplace Victimization of Women," in Sexual Harassment: Theory, Research, and Treatment (Needham Heights, MA: Allyn \& Bacon, 1997), 5-28; Henning et al., "Workplace Harassment among Staff in Higher Education," among numerous others.

16. Hilary J. Gettman and Michele J. Gelfand, "When the Customer Shouldn't Be King: Antecedents and Consequences of Sexual Harassment by Clients and Customers," Journal of Applied Psychology 92, no. 3 (2007): 757-70, https://doi.org/10.1037/0021-9010.92.3.757; Lea B. Vaughn, “The Customer Is Always Right... Not: Employer Liability for Third Party Sexual Harassment," Michigan Journal of Gender $\mathcal{E}$ Law 9 (2003): 1-90; Ilya Kagan et al., "Sexual Harassment by Patients: The Difference Experience of Female Doctors, Nurses and Nurse Aides," Medicine and Law 34, no. 5 (2015): 17.

17. Gettman and Gelfand, "When the Customer Shouldn't Be King."

18. Yagil, "When the Customer Is Wrong."

19. Gettman and Gelfand, "When the Customer Shouldn't Be King."

20. Yagil, "When the Customer Is Wrong."

21. Gettman and Gelfand, "When the Customer Shouldn't Be King."

22. Vaughn, "The Customer Is Always Right... Not."

23. Roxanne Nelson, "Sexual Harassment in Nursing: A Long-Standing, but Rarely Studied Problem," AJN: American Journal of Nursing 118, no. 5 (May 2018): 19-20, https://doi.org/10.1097/01.NAJ.0000532826.47647.42.

24. Carrie A. Moylan and Leila Wood, "Sexual Harassment in Social Work Field Placements: Prevalence and Characteristics," Affilia 31, no. 4 (November 2016): 405-17, https://doi.org/10.1177/0886109916644643.

25. Fitzgerald, Swan, and Magley, "But Was It Really Sexual Harassment?"; Jana L. Raver and Michele J. Gel- 
fand, "Beyond the Individual Victim: Linking Sexual Harassment, Team Processes, and Team Performance," Academy of Management Journal 48, no. 3 (June 2005): 387-400, https://doi.org/10.5465/amj.2005.17407904; Willness, Steel, and Lee, "A Meta-Analysis of the Antecedents and Consequences of Workplace Sexual Harassment."

26. Vaughn, "The Customer Is Always Right... Not"; Willness, Steel, and Lee, "A Meta-Analysis of the Antecedents and Consequences of Workplace Sexual Harassment"; Gettman and Gelfand, "When the Customer Shouldn't Be King."

27. Yagil, "When the Customer Is Wrong"; Gettman and Gelfand, "When the Customer Shouldn't Be King"; Vaughn, "The Customer Is Always Right... Not."

28. Vaughn, "The Customer Is Always Right... Not."

29. Vaughn, "The Customer Is Always Right... Not."

30. Will Manley, “Will's World: No Laughing Matter This Month," American Libraries 24, no. 1 (January 1993):

2.

31. Jensen, "The State of Sexual Harassment in the Library."

32. Such as Jessica Olin and Michelle Millet, "Gendered Expectations for Leadership in Libraries-In the Library with the Lead Pipe," accessed February 6, 2019, /2015/libleadgender/.

33. Barbara Pease, “Workplace Violence in Libraries," Library Management 16, no. 7 (November 1995): 30-39, https://doi.org/10.1108/01435129510093764.

34. Pease, "Workplace Violence in Libraries."

35. Gettman and Gelfand, "When the Customer Shouldn't Be King."

36. Pease, "Workplace Violence in Libraries."

37. Pease, "Workplace Violence in Libraries."

38. Henning et al., "Workplace Harassment among Staff in Higher Education."

39. Willness, Steel, and Lee, "A Meta-Analysis of the Antecedents and Consequences of Workplace Sexual Harassment."

40. Willness, Steel, and Lee, "A Meta-Analysis of the Antecedents and Consequences of Workplace Sexual Harassment"; Louise F. Fitzgerald, Suzanne Swan, and Karla Fischer, "Why Didn't She Just Report Him? The Psychological and Legal Implications of Women's Responses to Sexual Harassment," Journal of Social Issues 51, no. 1 (April 1995): 117-38, https://doi.org/10.1111/j.1540-4560.1995.tb01312.x; Fitzgerald, Gelfand, and Drasgow, "Measuring Sexual Harassment."

41. Raver and Gelfand, "Beyond the Individual Victim"; Mark L. Lengnick-Hall, "Sexual Harassment Research: A Methodological Critique," Personnel Psychology 48, no. 4 (December 1995): 841-64, https://doi. org/10.1111/j.1744-6570.1995.tb01783.x; Michelle A. Donovan and Fritz Drasgow, “Do Men's and Women's Experiences of Sexual Harassment Differ? An Examination of the Differential Test Functioning of the Sexual Experiences Questionnaire," Military Psychology 11, no. 3 (1999): 265; Robert H. Faley et al., "Estimating the Organizational Costs of Sexual Harassment: The Case of the U.S. Army," Journal of Business and Psychology, n.d., 24.

42. Willness, Steel, and Lee, "A Meta-Analysis of the Antecedents and Consequences of Workplace Sexual Harassment."

43. Faley et al., "Estimating the Organizational Costs of Sexual Harassment: The Case of the U.S. Army."

44. Feldblum and Lipnic, "Select Task Force on the Study of Harassment in the Workplace."

45. The survey questions and our data are available in the data set: Allison Wisecup et al., "Sexual Harassment in Academic Libraries: Sexual Experiences Questionnaire Including Client Sexual Harassment Component, March 31, 2021," Data Set (Distributed by University of Colorado Boulder Institutional Repository, CU Scholar, March 31, 2021), https://doi.org/10.25810/bmq5-2044.

46. Louise F. Fitzgerald, Fritz Drasgow, Charles L. Hulin, Michele J. Gelfand, M. J., and Vicki J. Magley, "Antecedents and Consequences of Sexual Harassment in Organizations: A Test of an Integrated Model," Journal of Applied Psychology 82, no. 4 (1997): 578-89, https://doi.org/10.1037/0021-9010.82.4.578.

47. Barbara A. Gutek, Ryan O. Murphy, and Bambi Douma, "A Review and Critique of the Sexual Experiences Questionnaire (SEQ)," Law and Human Behavior 28, no. 4 (2004): 457-82, https://doi.org/10.1023/ B:LAHU.0000039335.96042.26.

48. Anne M. O'Leary-Kelly et al., "Sexual Harassment at Work: A Decade (Plus) of Progress," Journal of Management 35, no. 3 (June 2009): 503-36, https://doi.org/10.1177/0149206308330555.

49. Deborah A. Gerrity, "Male University Employees' Experiences of Sexual Harassment-Related Behaviors," Psychology of Men \& Masculinity 1, no. 2 (2000): 140-51, https://doi.org/10.1037//1524-9220.1.2.140; Gettman and Gelfand, "When the Customer Shouldn't Be King"; Moylan and Wood, "Sexual Harassment in Social Work Field Placements"; Maryati Omar, "Client Sexual Harassment: The Measure and Effects on Malaysian Professional Women" (University of Malaya, 2008).

50. Fitzgerald et al., "The Incidence and Dimensions of Sexual Harassment in Academia and the Workplace." 
51. Sandy Welsh and Annette Nierobisz, "How Prevalent Is Sexual Harassment? A Research Note on Measuring Sexual Harassment in Canada," Canadian Journal of Sociology / Cahiers Canadiens de Sociologie 22, no. 4 (1997): 505, https://doi.org/10.2307/3341695.

52. The GenIUSS Group, "Best Practices for Asking Questions to Identify Transgender and Other Gender Minority Respondents on Population-Based Surveys" (The Williams Institute), accessed January 28, 2019, https:// williamsinstitute.law.ucla.edu/wp-content/uploads/geniuss-report-sep-2014.pdf.

53. American Library Association, “Diversity Counts 2009-2010 Update, Tables Series A" (September 18, 2012), www.ala.org/aboutala/sites/ala.org.aboutala/files/content/diversity/diversitycounts/diversitycountstables2012. pdf.

54. Lynn Bowes-Sperry and Anne M. O'Leary-Kelly, “To Act or Not to Act: The Dilemma Faced by Sexual Harassment Observers," Academy of Management Review 30, no. 2 (April 1, 2005): 288-306, https://doi.org/10.5465/ amr.2005.16387886.

55. Feldblum and Lipnic, "Select Task Force on the Study of Harassment in the Workplace." 